\title{
Implementação de Atividades Num Hospital Público e de Ensino Visando À Qualidade Assistencial do Trinômio Pai-Mãe e Recém-Nascido
}

\author{
Tase, Terezinha Hideco; Tronchin, Daisy Maria R.; Medeiros, Valdete de \\ Hospital das Clínicas da Faculdade de Medicina de São Paulo - terezinha.tase@hc.fm.usp.br
}

Os serviços de saúde comprometidos com a qualidade têm empregado as melhores práticas a fim de atender as necessidades e as expectativas dos usuários. Tal premissa torna-se um desafio no setor público, tendo em vista as especificidades e características desse setor envolvendo os elementos de estrutura, de processo e resultado. no que tange, à gravidez de alto risco constatamos a exigência de profissionais de saúde capacitados e comprometidos com o cuidado devido à sua complexidade, representada pelas patologias associadas, pelas repercussões no estado emocional da mulher e do seu concepto, assim como na dinâmica familiar. o Alojamento Conjunto foi implantado tornando-se uma modalidade de atenção e definido como um sistema hospitalar, cujo método possibilita ao recém-nascido $(\mathrm{RN})$ permanecer ao lado da mãe na mesma área física, proporcionando a prestação dos cuidados, a manutenção do vínculo e o envolvimento da família. Nessas condições é possível estimular e praticar o aleitamento materno sob livre demanda, fortalecer os laços afetivos e proporcionar uma assistência humanizada. com vistas à assistência de saúde humanizada e de qualidade foi necessário a adequação dos recursos físicos e materiais e a contratação e capacitação dos recursos humanos, sobretudo, da equipe de enfermagem. Trata-se de um relato de experiência, cujo objetivo é descrever as principais implementações realizadas em um hospital público e de ensino o qual assiste gestante de alto risco para a instalação do alojamento conjunto. Assim, recorremos ao planejamento e execução de melhorias na área física, a aquisição de materiais e equipamentos que oferecessem espaço, conforto e apoio para a mãe, para o $\mathrm{RN}$, para o pai ou acompanhante. no que tange, à assistência de enfermagem buscamos o aprimoramento do conhecimento técnico-científico para o cuidado integral, com alto grau de competência profissional, por meio das evidências científicas e programa de capacitação dos profissionais. Além disso, houve a contratação de seis enfermeiros e 14 técnicos de enfermagem. a revisão dos processos assistenciais e dos protocolos gerenciais vem proporcionando mudanças dirigindo a assistência com base na competência profissional e na relação de respeito dos profissionais de saúde envolvidos com o trinômio. Essa experiência ao longo de um ano tem demonstrado transformações repercutindo em discussões, aprimoramento do conhecimento e troca de experiências entre a equipe multidisciplinar e o trinômio. por conseguinte, conduz a outras reflexões acerca de nossa responsabilidade em manter e aprimorar a assistência ao trinômio, considerando o seu contexto sociocultural e familiar.

Tase, Terezinha Hideco; Tronchin, Daisy Maria R.; Medeiros, Valdete de. Implementação de Atividades Num Hospital Público e de Ensino Visando À Qualidade Assistencial do Trinômio Pai-Mãe e Recém-Nascido.. In: Anais do Congresso Internacional de Humanidades \& Humanização em Saúde [= Blucher Medical Proceedings, num.2, vol.1]. São Paulo: Editora Blucher, 2014. ISSN 2357-7282

DOI 10.5151/medpro-cihhs-10484 